\title{
Between old and new: Brandom's analytic pragmatism
}

Critical notice of:

Between Saying and Doing: Towards an Analytic Pragmatism

By Robert B. Brandom

Oxford University Press, 2008. Pp. xxi + 251. ISBN 978-0-19-954287-1. Hbk £18.99

(\$38.00).

This is a pre-print of an article whose final and definitive form is due to be published in the International Journal of Philosophical Studies 17 (2009), available at http://journalsonline.tandf.co.uk.

\section{Introduction}

Robert Brandom's follow-up to the monumental Making it Explicit ${ }^{1}$ - in anticipation of which many have waited with baited breath—has finally appeared. Between Saying and Doing $^{2}$ is the text of his John Locke Lectures, delivered at the University of Oxford in 2006. Although Brandom is keen to insist that the two enterprises the books contain 'are largely orthogonal', many of the prominent themes in the most recent work will be familiar to readers of the earlier, including the connection between meaning and use, the expressive role of logic, the normative notions of commitment and entitlement, and the relation between the implicit and the explicit. Nonetheless, each is reframed here in the light of an ostensibly 'new metatheoretic conceptual apparatus' (p. 1), and it is the primary aim of the book to outline and demonstrate the utility of that apparatus, rather than argue for any specific thesis (although Brandom 
does plenty of that along the way). In doing so, Brandom hopes to lay the foundations for what he calls an 'analytic pragmatism'.

Brandom has certainly produced a fascinating, if dense and difficult, book, replete with interesting, controversial and interlocking ideas concerning intentionality, semantics, modality, normativity, logic and, most of all, their interrelations.

Throughout, Brandom characteristically and illuminatingly seeks to locate these ideas within a philosophical tradition populated by such figures as Sellars, Wittgenstein, Kant and, increasingly, Hegel. As mentioned, the relevant issues are articulated and defended with the aid of what are presented as novel analytical tools. However, while the apparatus certainly has an unfamiliar appearance, and while I do not profess to have fully mastered it, it is not at all clear to me that the method underlying the machinery is really so new, or that the results of employing it are not results that could be otherwise achieved or expressed.

\section{$2 \quad$ Meaning-use relations}

So as to engage critically with Brandom's proposal, I shall outline the basic components of the complex apparatus he introduces, which are first introduced against the background of what Brandom describes as the 'epic confrontation of analytic philosophy and pragmatism, especially Wittgensteinian'. According to Brandom, analytic philosophy is best understood as having 'at its center a concern with semantic relations between [...] "vocabularies", (p. 1). While they might characterise it differently (for example, in terms of supervenience, truth-making, definition, translation, or reduction), analytic philosophers seek to specify what relation holds (if any) between, say, descriptive and normative statements, or physical 
and intentional statements, and typically do so with the aid of logical vocabulary. No doubt many would reject this generalisation, but for present purposes I shall grant it.

According to Brandom, pragmatism challenges the analytic project by privileging pragmatics (broadly construed) over semantics, by 'displacing the notion of meaning in favour of that of use' (p. 3). ${ }^{3}$ Starting out from the putative insight that vocabularies mean what they do in virtue of the use to which they are put, the pragmatist denies that 'linguistic practices and the vocabularies caught up in them [...] typically admit of specification in terms of underlying principles specifiable in other vocabularies'. The principal reason for this is the allegedly 'essentially dynamic character of linguistic practice'. No principle for the use of an expression could be informatively or finitely articulated, since 'what practical extensions of a given practice are possible for the practitioners can turn on features of their embodiment, lives, environment, and history that are contingent and wholly particular to them' (pp. $5-6)$.

It is Brandom's grand ambition to reconcile analytic philosophy and pragmatism. Specifically, in addition to considering semantic relations between vocabularies, with analytic philosophy, Brandom invites us to consider, with pragmatism, relations between vocabularies and practices-or-abilities, as well as between practices-or-abilities themselves. ${ }^{4}$

Brandom proceeds to introduce a number of such 'meaning-use relations' (MURs), which he represents diagrammatically. $P V$-sufficiency 'obtains when engaging in a specified set of practices [...] is sufficient for someone to count as deploying a specific vocabulary'. VP-sufficiency obtains when a 'vocabulary is sufficient to specify' a practice. Where a vocabulary, V1, is VP-sufficient for characterising a practice PV-sufficient for deploying another, V2, a further 
'pragmatically mediated' relation between the vocabularies results, namely that V1 is a pragmatic metavocabulary for V2. An especially interesting case is when V1, the pragmatic metavocabulary, is 'weaker in expressive power' than V2, i.e. when there are things one can say using V2 that one cannot say using V1 (pp. 9-11). Brandom calls this pragmatic expressive bootstrapping.

Brandom adds to this basic set of MURs. PV-necessity 'obtains when one cannot deploy a certain vocabulary without engaging in the specified practice' (p. 28). $P P$-necessity obtains when being able to participate in a practice, $\mathrm{P} 1$, is necessary for being able to participate in another, $\mathrm{P} 2$. This in turn 'induces a resultant pragmatically mediated semantic relation between vocabularies', namely $V V$-necessity (pp. 12-13). V1 is VV-necessary for V2, if P1 is PV-sufficient for deploying V1 and PP-necessary for P2, which is PV-sufficient for deploying V2.

A further relation - put to a lot of use-is $P P$-sufficiency, which 'holds when having acquired one set of abilities means one can already do everything one needs to do, in principle, to be able to do something else' (p. 26). There are at least two ways in which PP-sufficiency might obtain. First, P1 might be 'algorithmically elaborated' into $\mathrm{P} 2$, in the sense that exercising the abilities required for $\mathrm{P} 2$ just is exercising the abilities involved in $\mathrm{P} 1$ in a certain fashion. Corresponding to this is $V V$-sufficiency, which obtains between V1 and V2 when the practice PV-sufficient for deploying V1 is algorithmically PP-sufficient for the practice PV-sufficient for deploying V2. In such a case, V1 may be described as a semantic metavocabulary sufficient to 'characterise' V2 (p. 39). A second way in which P1 might be PP-sufficient for P2 is when 'as a matter of contingent empirical fact $[\ldots]$ anyone who has the one set of capacities can be brought to have the other as well' by 'learning or training' (pp. 8384). 
These MURs can be further combined into still more complex relations. The most important, for Brandom, is $L X$, which obtains between V1 and V2 when, first, P1 is PV-necessary for deploying V1 and (algorithmically) PP-sufficient for P2, second, P2 is PV-sufficient for deploying V2, and finally, V2 is VP-sufficient for specifying P1. When this obtains, V2 is elaborated from and explicative of V1. What one says in employing V2 is implicit in the deployment of V1.

\section{The apparatus in action}

In the abstract, this bewildering array of relations can be hard to keep a handle on. Accordingly, Brandom hopes to demonstrate the power of his apparatus through applying it to a number of philosophically significant cases, specifically the relations among logical, intentional, semantic, modal and normative vocabularies and the practices of employing them. In this section, I shall briefly outline some of Brandom's analyses.

Brandom aims to show that logical vocabulary stands in the LX relation to any vocabulary whatsoever. The argument is, very roughly, as follows. Asserting and inferring are PP-necessary for one another, and both are PV-necessary for deploying any vocabulary (form an essential part of any 'discursive practice'). One is not a language-user unless one can make claims and use them to draw inferences. Moreover, 'the abilities to make assertions and sort inferences into those that are and those that are not materially good ones' can be algorithmically elaborated into (are PP-sufficient for) an ability 'PV-sufficient to deploy a further vocabulary, namely conditional locutions' (p. 44). A language-user's existing abilities to respond practically to an inference by treating it as good and to respond to a stimuli by making an assertion using non-logical vocabulary can be reconfigured into an ability to respond to what 
she takes to be a materially good inference by making an assertion using the conditional and to respond to such assertions by treating an inference as good.

In Brandom's view, deploying the conditional—saying, for example, 'If the ball is red, then it is coloured'-allows one to specify (is VP-sufficient to describe) what one is doing when one treats an inference as materially good. And since deploying the conditional allows one to say that one claim follows from another when this cannot be said in the vocabulary whose use the ability of employing conditionals is elaborated from, we have a case of expressive pragmatic bootstrapping.

Suggestively, Brandom adds that this conclusion, if true, vindicates the analytic philosopher's traditional appeal to logical vocabulary in analysing semantic relations. Since the logical vocabulary is an elaboration, in Brandom's sense, of the non-logical vocabulary to be analysed, logical vocabulary adds nothing that is not already present (it is 'semantically transparent'). In addition, since logical vocabulary allow one to say things about the analysed vocabulary that could not otherwise be expressed, its use can be genuinely instructive (it is 'analytically efficacious') (pp. 52$53)$.

Brandom proceeds to argue that normative and modal vocabulary likewise stand in LX relations to descriptive vocabularies in general. Even more roughly, the respective arguments run as follows. First, the ability to infer - to tell in practice what a claim commits one to and when one is entitled to those commitments-is PVnecessary for deploying any vocabulary. Hence, 'discursive practitioners must be able in practice to take or treat each other and themselves as exhibiting normative statuses' (p. 114). This ability is algorithmically PP-sufficient for an ability PV-sufficient for normative vocabulary, an ability to respond to a normative status by explicitly saying, for example, ' $S$ is committed to $p$ '. This normative vocabulary in turn stands in the 
VP-sufficiency relation to discursive practice, since it allows subjects to codify aspects of that practice.

Second, the ability to infer is PV-necessary for deploying any vocabulary. Hence, to be able to infer one must be able to distinguish, for each commitment, the range of further commitments that would, and would not, 'infirm or defeat it' (p. 79). This ability is algorithmically PP-sufficient for an ability PV-sufficient for modal vocabulary, an ability to explicitly say, for example, 'It is not possible that $p$ and not$q$ '. This modal vocabulary in turn stands in the VP-sufficiency relation to discursive practice, since it allows subjects to codify aspects of that practice.

Interestingly, and controversially, Brandom argues that normative vocabulary occupies a privileged position, insofar as it can serve 'as a pragmatic metavocabulary for logical vocabulary, including modal vocabulary’ (p. 119). In short, Brandom explains the implicitly modal notion of incompatibility in terms of the normative notions of commitment and entitlement $-p$ and $q$ are incompatible if commitment to $p$ precludes entitlement to $q$. In turn, Brandom employs this notion of incompatibility in a modal formal semantics - one which makes no direct use of the notion of truthwith which he defines various other logical notions, including negation and entailment, and modal notions, including necessity and possibility. In a final and intriguing chapter, whose dark details I cannot adequately enter into here, Brandom argues that normative and modal vocabularies - the abilities to use which can be algorithmically elaborated from the ability to use any vocabulary whatsoever - can together be used to specify (are VP-sufficient for) discursive practices in general; specifically, they make explicit the intentionality of language-use.

\section{$4 \quad$ New for old}


Having introduced Brandom's 'meaning-use analytic' apparatus and considered, if cursorily, its application, it is time critically to examine Brandom's latest enterprise. No doubt, one might be tempted to challenge certain of Brandom's specific theses or the arguments he offers in their support. But, in line with the aims of his book, I shall focus on the more general, metatheoretical issue of how new Brandom's approach really is. ${ }^{5}$ That is, I shall examine whether Brandom succeeds in his ambition of 'ushering in a new phrase of the analytic project' (p. 32) through introducing 'distinctive' pragmatically mediated analytic relations 'quite different from, for instance, definability, translatability, reducibility, and supervenience' (p. 11). While the new-fangled system of MURs certainly has an alien appearance, as do the theses advanced with its help, underneath it all there seems to be lurking a rather traditional philosophy.

Consider, for example, Brandom's characterisation of one aspect of Sellars' critique of phenomenalism (p. 12). Reformulating the argument in terms of MURs, Sellars claims, says Brandom, that practices PV-sufficient for 'is'- $\Phi$ talk are PPnecessary for the practices PV-sufficient for 'looks'- $\Phi$ talk. But, one might ask, what does this amount to? As Brandom acknowledges, it amounts to saying_-in the terms of analytic philosophy—-that 'looks' $\Phi$ talk semantically presupposes 'is'- $\Phi$ talk. In that case, it would seem that the upshot of Sellars' analysis, as Brandom presents it, is a rather traditional claim.

Moreover, the claim of VV-necessity (or semantic presupposition) is surely not one that could only be arrived at through the use of Brandom's apparatus. Consider, in this regard, Daniel Bonevac's comments:

Sellars argues at some length that being $\Phi$ is logically prior to looking $\Phi$. But that conclusion requires no sophisticated argument. 'Looks red', for example, is not an 
idiom; its meaning is a function of the meanings of 'looks' and 'red'. All one needs to establish that being $\Phi$ is logically prior to looking $\Phi$ is an appeal to compositionality. ${ }^{6}$ One can certainly appreciate this point so formulated - and Bonevac has no trouble in so formulating it — without having to view the semantic relation as 'mediated' by a pragmatic one (although it might well be so mediated).

So far, I have suggested that one of the claims that Brandom's meaning-use analysis delivers is in fact recognisably traditional and (so) a claim that could be, and indeed has been, arrived at in a more orthodox fashion. This in turn strongly indicates that Brandom's 'addition' of a mediating layer of practices does not add anything bearing argumentative clout to the version offered in purely of semantic terms.

Note also that the 'additional' pragmatic story is actually part and parcel of the original argument. Indeed, Sellars himself happily switches interchangeably between the semantic and pragmatic levels:

the concept of looking green, the ability to recognize that something looks green, presupposes the concept of being green, and [...] the latter concept involves the ability to tell what colour objects have by looking at them. ${ }^{7}$

Sellars apparently treats the semantic and pragmatic stories as two sides of the same coin, rather than viewing the latter in this instance as a deepening of or addition to the former.

Of course, Brandom might reply that Sellars is ready to proceed in this way, since he is himself a pragmatist, whose methodological approach Brandom is developing. Consider instead, then, Brandom's example of indexical vocabulary. Since our interest is in the general framework, I shall not enter into the details of Brandom's arguments. His guiding idea is that 'in spite of the semantic irreducibility of indexical to non-indexical vocabulary, it is possible to say, in entirely nonindexical terms, what one must $d o$ in order to be deploying indexical vocabulary 
correctly' (p. 25). According to Brandom, non-indexical vocabulary is VP-sufficient to describe the ability PV-sufficient for indexical vocabulary. Moreover, that ability can be algorithmically elaborated from the ability PV-sufficient for non-indexical vocabulary. In turn, indexical vocabulary is VP-sufficient to specify features of the ability PV-sufficient for non-indexical vocabulary, which is to say that the vocabularies stand in the LX relation. Finally, since the ability to deploy nonindexical vocabulary is algorithmically PP-sufficient to deploy indexical vocabularies, the former vocabulary is VV-sufficient for the latter.

This last point, which Brandom does not explicitly make, amounts to the claim that indexical vocabulary is a semantic metavocabulary for non-indexical vocabulary. In that case, however, the relation of VV-sufficiency looks suspiciously like or approximates closely to what analytic philosophers traditionally call supervenience or truth-making. If the VV-sufficiency relation holds, facts that one might state using indexical vocabulary supervene upon or are made true by facts one might state using non-indexical vocabulary; the latter are sufficient for the truth of the former. As the LX relation running between the vocabularies in the converse direction shows, what is expressed using indexical terms is implicit in what is expressed using non-indexical terms.

It seems, once again, that Brandom's meaning-use analysis results in a remarkably familiar philosophical claim, albeit one dressed in unfamiliar clothes. To appreciate this, compare Brandom's approach to one found in another set of John Locke Lectures, namely Frank Jackson's From Metaphysics to Ethics. ${ }^{8}$ This provides an especially interesting comparison for a number of reasons. First, Jackson's workwhich aims to identify 'when matters described in one vocabulary are made true by matters described in another" ${ }^{9}$ - falls squarely within the analytic tradition as 
Brandom characterises it. Second, Jackson is as explicit and clear as Brandom concerning the metatheoretical apparatus with which he operates. Third, Jackson too examines the relation between facts stated with indexical vocabulary and those stated with non-indexical vocabulary.

Like Brandom, Jackson claims that 'egocentric or de se content is irreducibly so'. ${ }^{10}$ Nonetheless, and effectively like Brandom, he argues that 'the truth-value of each and every token with egocentric content supervenes on the full de dicto story about the world' (pp. 19-21). Though they present their views in very different ways, both Brandom and Jackson agree that the story told in non-indexical terms is sufficient for the story told in indexical terms. It is unclear, then, how Brandom's approach differs in substance, if not style, from that of a traditional analytic philosopher like Jackson. Indeed, in strikingly Brandomian terms, Jackson claims to be 'distinguishing what appears explicitly in an account from what appears implicitly in it' 11

Brandom might point to the relation of PP-sufficiency underlying VVsufficiency, about which Jackson is silent, to highlight what distinguishes the approach of the analytic pragmatist:

What does this meaning-use analysis tell us? It shows us that, and how, anyone who knows how to use non-indexical vocabulary already knows how to do everything she needs to, in principle (a qualification we can cash out precisely, in terms of algorithmic elaborative abilities), to deploy indexical vocabulary. So one could never be in the position of understanding non-indexical vocabulary but being mystified by indexical vocabulary (p. 67).

While it is true that Jackson is principally concerned with how vocabularies are 'interconnected' ${ }^{12}$, i.e. with semantic relations, he also allows that there are abilities (in Brandom's broad sense) PV-sufficient for vocabularies. Jackson, like Brandom, is 
a functionalist (again, in a broad sense), accepting that 'it is the functional role of a belief that determines its content'. ${ }^{13}$ Moreover, Jackson could readily allow the ability PV-sufficient for non-indexical vocabulary could be algorithmically elaborated into the ability PV-sufficient for indexical vocabulary (that a PP-relation corresponds to the VV-relation on which he focuses). The important issue is whether this adds anything to the story at the semantic level, especially as one can arrive at and formulate the VV-sufficiency point without going via the observation about PPsufficiency. That the facts characterised in indexical terms supervene upon those characterised in non-indexical terms might be sufficient to demystify the former (on the assumption that they are mystifying in the first place); it is far from self-evident that reformulating this point in terms of the abilities to deploy the relevant terms is more efficacious in addressing our philosophical concerns. Suppose, with Jackson, that non-indexical statements entail indexical statements. Do we learn anything more of relevance about this semantic relation by being told that the ability to state the latter is a derived from the ability to state the former? It is not clear that we do. As above, one might view the semantic and pragmatic stories as two sides of the same coin, rather than providing a superficial explanation and an underlying one respectively.

Needless to say, I cannot decisively settle here whether or not the pragmatically augmented version of the analysis is more effective than the merely semantic; the present point is only that it is not obvious that it is or that it contains anything not already found (albeit not in so many words) in traditional analytic philosophy.

Brandom might urge that what is distinctive about the meaning-use analysis is not that it reveals that non-indexical vocabulary provides a semantic metavocabulary 
for indexical vocabulary, but rather that it demonstrates that indexical vocabulary, like logical vocabulary, is a pragmatic metavocabulary for non-indexical vocabulary, i.e. VP-sufficient for specifying the practice of using it (specifically, in Brandom's view, as involving the immediate acknowledgement of practical commitments). However, to make a more substantive critical point, this claim is misleading. Originally, VPsufficiency was introduced as obtaining when a vocabulary is sufficient to 'specify' a practice, to 'say' what its practitioners are doing (p. 10). But in this sense indexical vocabulary is not VP-sufficient for the use of non-indexical vocabulary. ${ }^{14}$ In saying, 'I am jogging now', I am not saying anything about linguistic practices, but instead about what I am doing, namely that I am jogging now. So, I am not making explicit features of what a subject does when she uses non-indexical vocabulary. It would be more felicitous to say that, on Brandom's analysis, when using indexical vocabulary, one is explicitly doing something with certain words that one could otherwise only do implicitly.

Now that might be both true and interesting (I suspect it is). But it is not properly-speaking VP-sufficiency (as Brandom defines it). What Brandom is actually offering is an account of the functional role (pragmatics) of sentences involving indexical vocabulary, that is, a PV-sufficiency claim about what use a certain sort of expression must possess in order to bear the distinctive kind of meaning that it does (specifically, for Brandom, it must function as the immediate acknowledgement of a practical commitment). We have already seen, however, that PV-sufficiency claims of this sort are advanced by traditional analytic philosophers and, furthermore, do not obviously contribute anything additional to the analytic story told merely at the semantic level (about the relation between matters described in indexical vocabulary 
and those described in non-indexical vocabulary). This excursus, then, has done nothing more to show that Brandom's apparatus makes a distinctive contribution.

It seems, therefore, that Brandom's 'new synthesis of pragmatic and analytic philosophy' (p. 30) might not be so new. A further respect in which Brandom's project is more similar to traditional analytic philosophy than he suggests is in his response to "the weightiest, deepest, and most important sort of objection to the classical project of philosophical analysis' (p. 203). Brandom claims that one respect in which his analytical approach qualifies as pragmatist, and so novel, is in incorporating 'the insights of the later Wittgenstein' (p. xii). However, without needing to take a stand on Wittgenstein exegesis, ${ }^{15}$ Brandom's enterprise is not 'pragmatist' in a Wittgensteinian sense according to his own interpretation of the later work.

Recall that, according to Brandom, Wittgenstein insists that the 'dynamic' character of language use cannot, in general, be captured by finite, articulable principles expressed in independent terms. Brandom, however, aims to show that the use of various vocabularies, including logical, can be algorithmically decomposed into more basic uses of other vocabularies, which uses can be specified in independent terms, and that certain vocabularies can be deployed informatively to characterise others. These endeavours seem premised on the idea or designed to show that Wittgenstein is wrong, at least for certain tracts of language. It is unclear, then, to what extent Brandom genuinely 'incorporates', rather than simply rejects, Wittgensteinian pragmatism. (This is not to say that there are not other pragmatist dimensions to Brandom's philosophy.)

\section{Conclusion}


I have expressed doubts about the novelty of the approach Brandom advances. Both its proximity to pragmatism and, especially, its distance from traditional analytic philosophy (as he characterises both) seem overstated. VV-sufficiency and -necessity claims are the traditional fodder of analytic philosophy (as Brandom describes it) and can be arrived at without the apparatus of MURs. That underlying them are pragmatic relations might not be urgent news.

The focus has primarily been on Brandom's metatheoretic apparatus. I have said little about the specific ideas Brandom advances in the course of developing that apparatus, many of which seem to me interesting, often plausible and well-supported, and certainly worth attending to. They deserve and will no doubt receive considerable critical scrutiny. The reservations concern only whether Brandom's machinery of MURs is required in order to formulate, appreciate or debate those ideas. Similarly, I have not challenged the guiding thought that what an expression means is related to its use; on the contrary, it seems entirely right to view investigations of meaning and of a certain sort of use as two sides of the same coin.

University of Southampton

Daniel Whiting

\section{Notes}

${ }^{1}$ R. B. Brandom, Making it Explicit: Reasoning, Representing, and Discursive Commitment (Cambridge, Massachusetts: Harvard University Press, 1994). Since its publication, Brandom's Articulating Reasons: an Introduction to Inferentialism (Cambridge, Massachusetts: Harvard University Press, 2000) has also appeared, but it is primarily a rehearsal and in places exact reproduction of ideas found in Making it Explicit. Brandom has also produced Tales of the Mighty Dead: Historical Essays in the Metaphysics of Intentionality (Cambridge, Massachusetts: Harvard University 
Press, 2002). This, however, is a collection of scholarly pieces and, while they contain a number of interlocking (Brandomian) themes, they do not add up to a unified dissertation.

${ }^{2}$ R. B. Brandom, Between Saying and Doing: Towards an Analytic Pragmatism (Oxford: Oxford University Press, 2008). All references will be this text unless otherwise indicated.

${ }^{3}$ Brandom's convention, which I follow here, is to mark the names of concepts by underlining them.

${ }^{4}$ Brandom uses the terms 'practice' and 'ability' pretty much interchangeably. Since nothing of importance hangs on this, I shall do the same.

${ }^{5}$ A related issue that I shall not address is how novel Between Saying and Doing is with respect to Brandom's own earlier work, particularly Making it Explicit. Not only, as mentioned above, are many of the themes present in Between Saying and Doing to be found in Making it Explicit but, in addition, it seems that the whole point of the analytic apparatus he introduces in the former depends to a large part on a claim that receives detailed defence only in the latter, namely that 'the only explanation there could be for how a given meaning gets associated with a vocabulary is to be found the use of that vocabulary: the practices by which that meaning is conferred or the abilities whose exercise constitutes deploying that vocabulary with that meaning'. Only if one accepts that an expression means what it does 'in virtue of' its use would one buy into Brandom's latest enterprise of 'meaning-use analysis', of articulating 'a logic of the relations between meaning and use' (pp. 8-9). To this extent, Between Saying and Doing is heavily indebted to Making it Explicit, despite Brandom's insistence that they are 'distinct projects' (p. 234). 
${ }^{6}$ D. Bonevac, 'Sellars vs. the Given', Philosophy and Phenomenological Research 64 (2002), pp. 4-5.

${ }^{7}$ W. Sellars, Empiricism and the Philosophy of Mind (Cambridge, Massachusetts: Harvard University Press, 1997), §18.

${ }^{8}$ F. Jackson, From Metaphysics to Ethics: a Defence of Conceptual Analysis (Oxford: Oxford University Press, 1997).

${ }^{9}$ From Metaphysics to Ethics, p. 41.

${ }^{10}$ Jackson focuses exclusively on the use of indexicals to express de se contents, but this does not bear significantly on the issues at hand.

${ }^{11}$ From Metaphysics to Ethics, p. 2.

${ }^{12}$ From Metaphysics to Ethics, p. 29.

${ }^{13}$ F. Jackson, with D. Braddon-Mitchell, Philosophy of Mind and Cognition: an Introduction $2^{\text {nd }}$ ed. (Oxford: Blackwell, 2007), p. 188. See also the remarks on concept-possession in From Metaphysics to Ethics, pp. 158-160.

${ }^{14}$ I think one could make similar point with respect to Brandom's claim that logical vocabulary is VP-sufficient to specify non-logical vocabulary.

${ }^{15}$ As it happens, and for what it is worth, I think Brandom nicely captures one 'particularist' (p. 7) dimension to Wittgenstein's later thought. For discussion of that dimension, and its relation to others in Wittgenstein's work, see my 'Particular and General: Wittgenstein, Linguistic Rules and Context', in The Later Wittgenstein on Language, ed. D. Whiting (Basingstoke: Palgrave, forthcoming 2009). 